\title{
Nutrition in Inflammatory Bowel Disease
}

\author{
Philipp Schreiner $^{\mathrm{a}}$ Maude Martinho-Grueber ${ }^{\mathrm{b}}$ Diana Studerus ${ }^{\mathrm{c}}$ \\ Stephan R. Vavricka ${ }^{\text {a,d }}$ Herbert Tilg ${ }^{\mathrm{e}}$ Luc Biedermann $^{\mathrm{a}}$ on behalf of the Swiss \\ IBDnet, an official working group of the Swiss Society of Gastroenterology
}

${ }^{a}$ Department of Gastroenterology and Hepatology, University Hospital Zurich, Zurich, Switzerland; ${ }^{b}$ Department of Gastroenterology, University Clinic of Visceral Surgery and Medicine, Inselspital, University of Bern, Bern, Switzerland; ' F Food on Record ${ }^{\circledR}$ Dietitians, Bale, Switzerland; ' Center of Gastroenterology and Hepatology, Zurich, Switzerland; ' Department of Internal Medicine I, Gastroenterology, Hepatology, Metabolism and Endocrinology, Medical University Innsbruck, Innsbruck, Austria

\section{Keywords}

Diet · Crohn's disease $\cdot$ Ulcerative colitis

\begin{abstract}
Background: Westernization, above all associated changes in diet, has been postulated to be one of the most important factors contributing to the increasing incidence in inflammatory bowel disease (IBD), consisting mainly of Crohn's disease and ulcerative colitis. Summary: Diet represents a crucially important and intuitively relevant topic for IBD patients. Although a substantial number of patients are prone to follow dietary advice from a variety of sources, including the lay press, there is intriguingly little scientific evidence for such an incitement. This may result in physicians being insufficiently informed about various aspects of nutrition, precluding adequate guidance of their patients with IBD. Importantly, IBD patients are at risk to develop deficiencies in iron, vitamin B12, folic acid, and several micronutrients, which may even be more pronounced in patients with active disease and those following a restrictive diet. This review aims to summarize the latest data from clinical and epidemiological studies investigating diet and its effect on the course of the disease and to outline the most important nutrient deficiencies in IBD patients. Key Messages: A western diet with an imbalance between omega-6 (n-6)/omega-3 (n-3) poly-
\end{abstract}

unsaturated fatty acids (PUFAs), in favor of n-6 PUFAs, may increase the risk of IBD, whereas a diet high in fruits and vegetables may decrease the risk of IBD. Many approaches to influence the course of IBD with dietary intervention exist. However, to induce or maintain remission in IBD with a change of diet is still in its infancy, and more dietary research is needed before we can apply it in daily practice. Patients with IBD, even in remission, have to be screened regularly for malnutrition.

(c) 2020 S. Karger AG, Basel

\section{Introduction}

The change of environmental factors, particularly the westernized lifestyle, combined with an alteration in diet, improved hygiene, vaccinations, increasing use of antibiotics [1], urbanization, and better access to medical supply as increased use of oral contraceptives [2-4], is thought to be one of the main drivers for the rising prevalence of inflammatory bowel disease (IBD) in westernized countries [5-9]. The highest impact of these factors to the development of IBD is probably exerted by the shift to a western diet characterized by high amounts of protein and (unsaturated) fat, but low amounts of vegetables, fibers, and fruits. Furthermore, this "Westernization" of dietary hab-

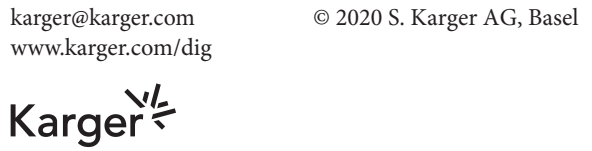


its may trigger a proinflammatory environment [10] in susceptible individuals through an alteration in the gut microbiome and a disturbed epithelial barrier function.

Although no guidelines exist advocating a specific diet during established disease [11-14], approximately $70 \%$ of IBD patients assume that diet influence their condition [15], nearly $60 \%$ of those consider diet to play a major role in triggering a relapse [16], and $16 \%$ of them are convinced that diet could initiate the disease [17]. Although IBD patients are highly interested in nutrition, only $8-16 \%$ are satisfied about the information they receive from their physicians [18]. Even half of them never received a dietary advice [19]. Interestingly, when trying to modify their dietary habits, patients rather focus on avoidance of certain foods instead of increasing the intake of dietary components with presumably more beneficial properties [20]. Specifically, IBD patients report to avoid spicy foods, vegetables, fruits, nuts, milk, red meat, soda, popcorn, dairy, high-fiber foods, coffee and beans, whereas an improvement of symptoms is rather attributed to banana, rice, and yogurt [21]. Additionally, a populationbased Canadian IBD Cohort could show that IBD patients may tend to substitute diets high in nutrients with sugar-laden beverages [22]. This apprehension may not be supportive for IBD patients, but rather fuels the restriction of certain foods in IBD patients with subsequent considerable impact on social life [17] and the potential risk of nutritional deficiencies, including iron, vitamin B12, calcium, and vitamin D [23]. This pattern of avoidance of specific food is even more pronounced in patients with stricturing Crohn's disease (CD) [24], rendering them a highly vulnerable patient group for deficiencies of micronutrients.

In this review, we summarize current knowledge and recent data on IBD and nutrition, highlight dietary components and their potential to modify course of IBD and discuss how to best recognize, treat, and prevent nutrient deficiencies in IBD patients.

\section{Nutrition and Risk of IBD}

The worldwide rising incidence of IBD [25] is paralleled by a "Westernization" of dietary habits in developing countries. It is therefore obvious that, in addition to a genetic influence [26], environmental factors, especially diet, undoubtedly play a major role in the development of IBD $[8,9,27]$.

The exact pathomechanism how diet promotes the development of IBD is still unknown, while 2 main mecha- nistic explanations are most prominent and need to be pointed out. First of all, diet has a profound impact on the composition of gut microbiota and changes of nutritional composition during early childhood or even later in life can favor an anti- or proinflammatory composition [28$30]$. Western diet is associated with a lower microbial diversity [31], a higher abundance of Bacteroides and Enterobacteriaceae [28-30, 32-34], and lower levels of Firmicutes [28], whereas a rural diet rather is linked to more short-chain fatty acids and a lower abundance of Enterobacteriaceae (Shigella and Escherichia) [32]. This change in diet in industrialized countries may subsequently shift the microbiota composition, which may promote a proinflammatory environment in susceptible patients.

Previous studies showed that patients with IBD have a lower diversity in their gut microbiota $[35,36]$ with an increase in invasive Escherichia coli [37], increase in Enterobacteriaceae family [38], and a reduced proportion of the phyla Bacteroidetes and Firmicutes. However, it is not clear, whether this dysbiosis represents a primary event triggered by a specific diet or is only a consequence of the disease itself.

Second, aside from microbial alterations, diet can also alter host immunity through many different mechanisms as increased intestinal permeability, decreased level of colonic Treg cells, and increased proinflammatory markers [39]. A western diet high in fat and sugar decreased mucus layer thickness, increased intestinal permeability, and increased tumor necrosis factor a secretion in susceptible mice [40].

There are many potential candidates being responsible for inducing an inflammatory reaction within the gut. Next to protein, lipids, and carbohydrates, also microparticles and food chemicals like emulsifiers or thickeners can contribute to intestinal and potentially subsequent systemic inflammation.

Interestingly, food additives, such as emulsifiers, may simultaneously act on both of the 2 aforementioned mechanisms [41], which will also be eluded below.

\section{Breastfeeding}

The first nutrient a human being receives either represents breast milk or formula feeding. The microbiota of infants who are breastfed differ from those who are formula fed [42], and nearly $30 \%$ of the bacteria within the gut derive from breast milk [43]. These early perturbations in the microbiome through diet can potentially increase the risk for disease. In the last decades, there has been a decrease in breastfeeding [43] and an increase in IBD [25]. Although this inverse association has not been investigated 
systematically yet, it certainly represents an interesting observation that should be further considered. Furthermore, many studies confirm a protective effect against future IBD development in breastfed infants [44, 45], whereas the strongest decrease in risk appears in children fed up to 12 months [46]. Aside from a decreased risk in developing IBD, a history of breastfeeding is inversely associated with a more favorable course in children having CD [47].

\section{Fat}

The intake of omega- $6(n-6)$ and omega-3 (n-3) polyunsaturated fatty acids (PUFAs) are among the most investigated nutrients with a potential association to IBD. $n-6$, respectively $n-3$, means that the last double bond is 6 , respectively 3 , carbon atoms away from the carboxyl end of the polyunsaturated carbon chain of fatty acid. N-6 PUFAs (linoleic acid [LA], arachidonic acid) are precursors to eicosanoids that are proinflammatory, whereas n-3 PUFAs (docosahexaenoic [DHA], eicosapentenoid and alpha-LA [ALA]) are precursors to eicosanoids believed to be anti-inflammatory [48]. LA and ALA are both essential fatty acids and thus have to be ingested, since the human body is not able to synthesize them. In sunflower oil as well as many other plant-based oils and margarine, high amounts of n-6 can be found. In contrary, n-3 can be found in high amounts in fatty fish and cod liver oil (DHA/eicosapentenoid) and also linseed oil and green leafy vegetables (ALA). The change of dietary habits in westernized countries is characterized by a rise of the n6/n-3 ratio [49].

One of the first epidemiological studies investigating dietary factors and the increase in IBD in Asian countries is a Japanese study that could demonstrate an association of an increased $n-6 / n-3$ ratio and a correlation to an increased incidence of $\mathrm{CD}$ [50]. A prospective cohort study [51] revealed a 2-fold increased risk of developing ulcerative colitis (UC) in patients with high intake of the n-6 PUFA LA. Furthermore, this study showed a $77 \%$ risk reduction in developing UC in patients with highest dietary intake of DHA acid, a n-3 PUFA. No decreased UC risk in patients eating high amounts of ALA could be demonstrated. Similar to the majority of studies on nutritional intake in IBD, no conclusions can be drawn about the causality of the results because of the study design. Another case-control study in Canadian children with $\mathrm{CD}$ demonstrated similar results with a lower risk for CD in children with a higher ratio of n-3/n-6 fatty acids [52]. The protective effect of $n-3$ fatty acids appears to apply not only in children but also in the adult population over 45 years [53]. In this cohort, total dietary n-3 intake, es- pecially docosahexanaenoic acid, was negatively associated with the development of UC.

These results find support in the prospective Nurses' Health Study cohort, where a higher long-term intake of n-3 PUFA was associated with a lower risk, and the higher intake of trans-unsaturated fatty acids was associated with an increased risk of UC [54].

However, a newer meta-analysis on this subject suggests a lack of association between fat intake and UC risk [55]. On the other hand, and in contrast to many other studies indicating n-3 PUFA as a protective dietary factor regarding IBD risk, a small Japanese case-control study found a positive association of n-3 PUFA and CD risk. The authors argue that the intake of oily fish high in n-3 PUFA would also necessarily increase fat intake as a whole and therefore potentially increase the risk of IBD [56].

To sum up, the currently available data are rather controversial, with most of the studies indicating an increasing risk of IBD with higher amounts of n-6 (or n-6/n-3 quotient, respectively) PUFAs and a possible protective effect of n-3 PUFA [54, 57]. One hypothesis of the inhomogeneous study results regarding fatty acids could be interindividual differences in the metabolism of n-3 and n-6 PUFA. Since dietary fatty acids are metabolized through enzymes that are genetically regulated, a genetic polymorphism at the CYP4F3 locus could modify dietary n-3 and n-6 PUFA beneficially in UC patients [58].

\section{Proteins}

Dietary proteins are derived from many different foods and can be classified into plant-based and animalbased protein sources. Evidently, considering the role of proteins in the diet, one has to distinguish between animal and vegetable proteins because animal-based protein sources often consist of more saturated fat than plantbased protein. In the epidemiological analysis of Shoda et al. [50], high intake of animal protein was the strongest independent risk factor for an increased incidence of CD. These findings are confirmed by a recently published prospective study (The E3N Prospective Study) conducted in French middle-aged women [59]. Like in the Japanese study, the positive association between protein intake and the risk of IBD was only seen with regard to animal but not vegetable protein. Other smaller studies and casecontrol series did show a trend toward a higher risk of IBD in patients, but without statistical significance [60].

However, meat consumption, as a high source of animal proteins, was found to increase the risk of IBD in a 
meta-analysis, but this association is ambiguous due to methodological flaws in the included studies [61]. Interestingly, the association of higher risk of IBD could also be demonstrated in high consumption of fish, another source of animal proteins $[59,60]$.

\section{Carbohydrates}

Although the data are inconclusive, most studies show a positive association between high intake of refined sugar and the development of CD [56,62], but not UC [56, 60]. However, in UC high intake of sucrose, a subtype of carbohydrates may be associated with a higher risk [63]. Despite recently published data $[64,65]$ showing an increased risk of UC in patients following a dietary pattern high in sugar and sweetened beverages, these findings could not be confirmed by data from 2 large prospective cohort studies from Sweden [66], in which a lack of an association between IBD and sweetened beverages could be demonstrated. However, this study did not distinguish between various artificial sweeteners, such as sucralose, saccharin, aspartame, cyclamate, and other sweeteners. Thus, it still remains possible that distinctive artificial sweeteners may promote the risk for IBD.

Opposed to the possible negative effect of sugars in general, fruits and vegetables, also rich in carbohydrates, may reduce the risk for CD, but not UC [52, 60, 67]. Specifically, many studies analyzed dietary fiber, which is found in high amounts not only in fruits and vegetables but also in whole grain and legumes. In a large prospective study, long-term intake of fiber, particularly from fruits and in a smaller part of vegetables, reduced the risk for $\mathrm{CD}$, but not for UC. In the group with the highest intake (24.3 g/day), there was a $40 \%$ lower risk for CD [68]. A meta-analysis could observe a significant dose - response relationship between fiber intake and $\mathrm{CD}$ risk with an decreasing risk of $13 \%$ for every $10 \mathrm{~g} /$ day increment in fiber intake [69]. Interestingly, fiber intake from whole grain or legumes had no effect on the risk for IBD [68]. Another US study showed that patients with great intake of fruits, vegetables, and fish had a 53\% lower risk of CD [70].

Another population-based prospective cohort study in Europe (EPIC-IBD) [71] supported the negative association of fiber intake and UC. In contrary to the US data of Ananthakrishnan et al. [68] showing a reduced risk for $C D$ in higher amounts of fiber intake, there was no association seen in the EPIC-IBD study. However, it has to be mentioned that other nutrients in vegetables or fruits may be responsible for reducing the IBD risk [63].

Nutrition in IBD

\section{Other Nutrients}

While vitamin D deficiency is highly prevalent in patients with established IBD [72], women with high 25-hydroxyvitamin D levels $(25[\mathrm{OH}] \mathrm{D})$ were shown to have a significantly lower risk reduction for developing $\mathrm{CD}$. For each $1 \mathrm{ng} / \mathrm{mL}$ increase in 25(OH)D plasma level, there could be shown a significant relative risk reduction of $6 \%$ for $\mathrm{CD}$ and a nonsignificant relative risk reduction of $4 \%$ for UC [73]. Another large observational trial (EPIC) did not show an association between prediagnostic $25(\mathrm{OH}) \mathrm{D}$ concentrations and the development of CD or UC [74].

Polyphenol with its classes flavonoids (flavonols, flavones, isoflavones, flavanones, anthrocyanidins, and flavanols), stilbenes (resveratrol), phenolic acids, and lignans have anti-inflammatory properties by ameliorating oxidative stress. Despite the potential positive mechanism, the EPIC cohort study [75] could not show a negative association of developing CD or UC and dietary polyphenol intake. Interestingly, flavones, abundant in thyme, rosemary and oregano, and resveratrol, present in grapes and wines, were associated with a lower risk for CD.

In summary, data of macronutrients and IBD risk are very inconclusive, but it can be highlighted that a western diet has a higher risk for IBD [60, 76], and specifically a diet with a high n-3/n-6 fatty acid ratio, rich in fruits and vegetables, reduces the risk of IBD. These statements find support in the latest ESPEN Guidelines [11].

\section{Diet and Course of Disease}

Although the association of diet and the development of IBD are highly interesting from an epidemiological and pathophysiological point of view, patients with an established diagnosis of IBD are interested in counseling on dietary modification aiming at ameliorating their disease course. Due to a lack of robust evidence, neither the ECCO, AGA, nor the ESPEN Guidelines recommend any specific diet during remission or active disease. A recently published Cochrane analysis concludes that an effect of any dietary interventions on CD or UC is uncertain [77]. Therefore, physicians are reluctant to provide any specific recommendations. Subsequently, the majority of patients continue their seek of dietary advice in various sources, including the Internet [78], where the quality and evidence basis of advice received hardly can surpass physician-based counseling. Thus, it is crucial that physicians are capable of providing certain dietary recommendations to patients and give orientation in the best possible way despite the clear-cut limitation of data. Three 
quarters of patients avoid - presumably unnecessary in the majority of instances - certain foods during remission to prevent a flare [16]. Even more patients avoid some food groups, especially proteins and fat, during flares due to fear of worsening symptoms $[19,79]$.

Regarding dietary modification, patients can either omit certain foods (elimination or exclusion diets) or add specific nutrients to the diet. It is crucial to differentiate between diets that may induce or maintain remission and consequently impact the course of disease and diets that only alleviate symptoms of IBD patients.

\section{Elimination/Exclusion Diets}

To explain the effect of exclusive diets, various mechanisms are currently being discussed. Some of the hypotheses feature a direct relationship between diet and IBD. For example, it has been suggested that diet can directly alter the composition of the microbiome. Other mechanisms suggest that dietary antigens trigger an immune response and finally diet influences the production of metabolites by the microorganisms living in the gut, which could have an impact on the mucus layer and the immune response [80].

Exclusive enteral nutrition (EEN) is the only really established diet in IBD patients, specifically in pediatric CD patients [81, 82]. Enteral nutrition, classified as elemental (based on amino acids, sugars, fats, vitamins, and minerals) or nonelemental (composed of oligopeptide or wholeprotein sources), is a liquid diet given by mouth or by feeding tube. Due to remission rates up to $80 \%$ in pediatric CD patients [83-85] following 6-8 weeks of EEN and a better efficacy and higher mucosal healing rates than corticosteroids [86], exclusion diet is considered as firstline treatment option in children with active luminal CD [87]. Similar remission rates can be achieved regardless of whether elemental or nonelemental regimens are used [81]. In adult CD patients, EEN is less effective than corticosteroids in inducing remission [81]. Furthermore, its poor palatability is the main reason for an exceedingly rare use in the adult population, and ECCO does not recommend EEN as therapy for inducing remission in adult CD patients [13]. However, in contrast to Europe, in Japan, EEN is used as primary therapy in adult CD patients [88] due to a Japanese study demonstrating higher rate of inducing remission and a better safety profile [89].

Due to the fact that partial enteral nutrition (PEN; only $50 \%$ elemental formula) reduces markedly the efficacy of inducing remission [90], the exclusion of all nutritional components representing a regular diet is probably the main mode of action in EEN.
There are insufficient data to use EEN as a maintenance therapy in adult or pediatric quiescent $C D$ patients [91]. However, a small Japanese randomized-controlled trial showed a lower relapse rate in patients assigned to a half elemental diet than that in the free diet group ( 34.6 vs. $64.0 \%$, multivariate hazard ratio 0.4 ) [92]. Additionally, there exists no indication in treating UC patients with EEN.

The Crohn's Disease Exclusion Diet (CDED) consists of a reduced intake of animal and saturated fat, glutencontaining grains, and emulsifiers, and an increase in fruits, vegetables, and resistant starch. Fifty percent of nutrition will be given as PEN. The reduction of dietary components is the most important mechanism, with allowed nutrients serving to reduce possible nutrient deficiencies and improve dysbiosis. The first study investigating CDED confirmed its effectiveness for the induction of remission in children with CD [93]. A further study demonstrated an induction of remission even for children failing biological therapy [94]. The data of the first randomized controlled study comparing CDED plus PEN versus EEN over 12 weeks in pediatric CD patients demonstrated similar response and remission rates by week 6 and sustained remission by week 12 [95]. Due to the easier treatment approach with the same efficacy, CDED has the potential to change the dietary recommendation in the future. There is an ongoing study with adult CD patients following CDED [96].

A novel diet, called CD-TREAT diet, tries to mimic EEN with an ordinary food diet, based on the composition of EEN [97]. The diet excludes specific components like gluten and lactose and is low in fibers. The advantage of the CD-TREAT diet to EEN is the palatability that is the limiting factor of EEN in adults. The study demonstrated a better tolerance of CD-TREAT in a healthy population and induced a similar effect to EEN on the fecal microbiome. After 8 weeks of CD-TREAT diet, 80\% (4/5) showed a clinical response and $60 \%(3 / 5)$ of the pediatric $\mathrm{CD}$ patients were in remission. A limitation certainly is the low number of only 5 active pediatric CD patients. Nevertheless, this novel approach in creating a diet based on the established EEN is interesting and has the potential to influence further dietary interventions.

The specific carbohydrate diet (SCD) is based on an exclusion of complex carbohydrates and processed foods. Monosaccharides, chicken, fish, and hard cheese are allowed. It is believed that complex carbohydrates are poorly absorbed in the intestinal tract and therefore result in inflammation. Only case series and small retrospective studies investigated this type of diet. In pediatric CD pa- 
tients, a symptomatic improvement could be demonstrated [98] as well as a mucosal improvement [99]. Another uncontrolled study showed a lack of mucosal healing with SCD in asymptomatic children with CD [100]. Recently, a small prospective study with 12 pediatric CD patients showed an improvement in clinical and laboratory parameters and changes in the fecal microbiome [101]. In adult patients, a clinical benefit could be shown through an online survey [102] and a case series of patients in remission following an SCD [103]. No studies in adults investigated laboratory or mucosal improvement.

Vegetarian diet is thought to presumably downregulate inflammation, whereas the western diet is proinflammatory and leads to dysbiosis [104]. Around 4\% of IBD patients follow a vegetarian diet $[19,105]$, whereas $17 \%$ of them restrict their diet due to belief of a benefit for their IBD [105]. A prospective cohort study investigating dietary factors in UC patients in remission could demonstrate that a higher intake of meat, particularly red meat, could increase the risk of a relapse in UC [106]. A Japanese study with $22 \mathrm{CD}$ patients in remission showed after 2 years a higher maintenance of remission in the semivegetarian diet (94\%) than in the omnivorous group (33\%). The semi-vegetarian diet consisted of a lacto-ovovegetarian diet with once-weekly fish and meat once every 2 weeks [107]. However, a cross-sectional analysis in Swiss IBD patients did not find an association of vegetarian diet and the course of IBD [105]. In a recently published prospective randomized trial (Food and Crohn's Exacerbation Study) [108], a reduced consumption of red meat and processed meat did not reduce the risk of symptomatic CD relapse in patients in remission. In addition, calprotectin was measured in a subset of patients, which showed no difference between the 2 groups.

Aside from a lower intake of protein or fat, vegetarians normally eat more vegetables and fibers than omnivores. In a mouse model, dietary fat induced colitis in interleukin-10-deficient mice, so that the authors conclude that certain fats may in genetically susceptible hosts promote IBD [109]. A recently published prospective study in UC patients found a 3 -fold increased risk of flare in patients consuming specific fatty acids like myristic acid (contained in palm and coconut oil and dairy fat) as well as in patients consuming ALA [110]. This finding may appear surprising as ALA belongs to the n-3 PUFA, which are thought to act anti-inflammatory [48]. However, there exists only one study showing a positive effect of $n-3$ PUFA regarding the course of disease in IBD. In patients with $\mathrm{CD}$, a fish-oil preparation containing a high dose of n-3 PUFA reduced the risk of a flare compared to patients receiving placebo capsules significantly with a $33 \%$ absolute reduction ( 28 vs. $69 \%, p<0.001)$ [111]. The results of this study were questioned because of the small sample size (78 patients). In a larger multicenter trial (EPIC-1 and EPIC-2) with $>1,000$ patients with CD n-3 PUFA did not reduce the risk of a flare over 1 year of follow-up [112]. A recently performed meta-analysis came to the same results as the EPIC studies, namely, that in IBD n-3 PUFAs have, despite the anti-inflammatory effect within the gut [113], no effect in maintaining remission [114].

A study by Llewellyn et al. [115] examined over 30 different diets in mice and demonstrated that a high-protein diet exacerbates colitis in mice and dietary psyllium, a specific fiber, ameliorated colitis, was associated with an increased bacterial diversity and reduced intestinal permeability. The authors propose that in mild to moderate IBD, a diet low in protein and high in selectively beneficial fiber could improve intestinal barrier function and reduce the microbial load. Furthermore, a study by Brotherton et al. [116] demonstrated a 40\% reduced flare risk in patients with CD who did not avoid fiber than in patients who avoided high-fiber diet. In UC, no difference could be shown. Patients with UC consumed more fibers than patients with CD; especially, female CD patients and $\mathrm{CD}$ patients with prior surgery and hospitalization consumed significantly less fibers. This may partly be due to conscious avoidance of fibers by CD patients with strictures due to fear of obstructive symptoms or because of recommendation of their treating physician. These results are in contrast to a systematic review conducted by Wedlake et al. [117], in which no effect of inducing remission or avoidance of flare regarding fiber intake in patients with CD could be shown. Avoidance of dietary fibers during a disease relapse represents a generally accepted recommendation [118]. Interestingly, a recently published trial investigating the risk for pouchitis and fruit consumption [119], a source high in fibers, could show a lower rate of pouchitis in UC patients consuming high intake of fruits. Furthermore, a higher microbial diversity in patients with high fruit consumption was found.

The Paleo diet, also referred to as the "Stone Age diet," is based on the concept that the nutrition of our ancestors was more natural and therefore healthier. It contains vegetables, fruits, nuts, seeds, small fish/shellfish, lean small game meat, and avoidance of processed foods [120]. An extension of the Paleo diet is the autoimmune protocol diet in IBD. This diet was investigated in an open-labeled uncontrolled trial with no improvement in inflammatory markers, but an amelioration of symptoms and a maintenance of remission in all 11 patients [121]. 
A similar anti-inflammatory diet with avoidance of lactose and processed complex carbohydrates, a higher intake of soluble fiber, leeks, onions, and fermented foods (pre- and probiotics), and a modified fat intake has been demonstrated to ameliorate symptoms in IBD patients in case series [122].

Although a Mediterranean diet is known to have beneficial effects on multiple chronic diseases [123, 124], with anti-inflammatory effects [125] and microbiotamodifying properties in CD patients [126], no randomized trial yet has systematically addressed Mediterranean diet in IBD. However, a randomized trial in UC patients is currently ongoing [127].

Fermentable, oligo-, di-, mono-saccharides, and polyols (FODMAPs) are poorly absorbed short-chain carbohydrates that may trigger abdominal bloating, abdominal pain, wind, and diarrhea. IBS-like symptoms are common in IBD and affect around 39\% and are more common in CD than in UC [128], and differentiating these symptoms to inflammation-related pain can be cumbersome and difficult.

A reduction of FODMAPs improved abdominal pain, bloating, and diarrhea in around a half of IBD patients [129]. Furthermore, a randomized, double-blind, placebo-controlled study in patients with IBD and IBS showed greater severity of pain, bloating, flatulence, and fecal urgency in patients consuming FODMAPs [130]. It is important to mention that a diet low in FODMAPs may improve symptoms in IBD patients but does not affect the inflammatory activity.

Interestingly, gluten-free diet is followed by around 5\% $[105,131,132]$ of IBD patients without celiac disease that is more than the double compared to the general population [132]. Almost half of the patients believe that this diet has a beneficial effect on their disease [105], although there are no studies showing that the inflammation would be positively influenced other than a clinical improvement [131]. Furthermore, the amelioration of abdominal symptoms in nonceliac gluten sensitivity presumably is more related to the avoidance of fructan rather than gluten [133], so that a low FODMAP diet seems to have a higher impact regarding symptoms than a gluten-free diet.

To complicate this topic even further, emulsifiers are used in many diets that could alter the gut microbiota and promote colitis $[41,134]$. This effect appears to be directly related to a microbiota-modulating property of some emulsifiers, as in unexposed mice undergoing fecal microbiota transplantation with stool from previously exposed mice, alterations in mucosal barrier could be induced. Titanium dioxide nanoparticles contained in pharmaceutical products represent another food additive, which has been shown to promote intestinal inflammation in dextran sodium sulfate colitis in mice [135]. Furthermore, splena, an artificial sweetener consisting of sucralose maltodextrin, promotes in CD-prone mice an alteration of the microbiome with $E$. coli overgrowth and increase of Proteobacteria what consecutively resulted in elevated myeloperoxidase activity and increased inflammation and gut damage [136].

We can summarize that there exist several dietary options to influence symptoms in IBD patients and diets that may alter the course of IBD. Patients who are interested in a special diet should, however, be advised by an IBD specialist or dietician due to the risk of malnourishment or nutritional deficiencies.

\section{Dietary Supplements}

ECCO's topical review on complementary medicine and psychotherapy in IBD [137] concludes that there is insufficient evidence to support the use of vitamins to induce or maintain remission in CD and UC.

Nevertheless, a prospective cohort study demonstrated that UC patients with $25(\mathrm{OH}) \mathrm{D}$ levels below $35 \mathrm{ng} / \mathrm{mL}$ had a higher risk of clinical relapse (OR 1.25, 95\% CI $1.01-1.56, p=0.044)$ [138].

In CD patients, $25(\mathrm{OH}) \mathrm{D}$ concentration is inversely associated with disease activity [139], and in UC patients, $25(\mathrm{OH}) \mathrm{D}$ concentration is inversely associated with mucosal inflammation [140]. Moreover, a longitudinal study demonstrated higher morbidity and disease severity in patients with low 25(OH)D levels [141].

Furthermore, oral supplementation with 1,200 IE vitamin $\mathrm{D} 3$ reduced the risk of relapse in $\mathrm{CD}$ patients insignificantly from 29 to $13 \%(p=0.06)$ [142]. Another study showed similar results, in which the quality-of-life scores improved and the CDAI score decreased after vitamin D supplementation, but there were no significant changes in laboratory or cytokine measures [143]. Additionally, a vitamin D substitution with 40,000 units cholecalciferol weekly for 8 weeks in active UC patients reduced intestinal inflammation and increased the abundance of Enterobacteriaceae without altering the fecal bacterial composition [144].

Although the data are not very robust, supplementing vitamin $\mathrm{D}$ is safe and well tolerated, so that it should be given to all IBD patients with vitamin D deficiency [145].

Anthocyanins, which occur in high amounts in blueberries and black raspberries, have anti-inflammatory and antioxidative effects [146]. An open pilot trial demonstrated that a daily standardized anthocyanin-rich bil- 
berry preparation in mild to moderate UC patients achieved remission and response in 63.7 and $90.9 \%$, respectively, after 6 weeks. Additionally, goji berry, another traditional supplement, has been shown to promote butyrate-producing bacteria and Bifidobacteria in interleukin-10-deficient mice, which in turn results in the suppression of intestinal inflammation [147].

Another trial investigating antioxidative properties could demonstrate a significant reduction of oxidative stress in $\mathrm{CD}$ patients receiving vitamin $\mathrm{E}$ and $\mathrm{C}$ supplementation. However, disease activity remained stable [148]. Aloe vera, an herbal preparation with potential anti-inflammatory effects in vitro [149], showed a significant clinical response compared to placebo (47 vs. $14 \%$, $p<0.05)$ in a double-blind, randomized, placebo-controlled trial but no significance in terms of clinical remission (30 vs. $7 \%, p=0.09$ ) or improvement ( 37 vs. $7 \%, p=$ $0.06)$ after 4 weeks [150]. Another antioxidant is quercetin, a flavonoid that is present in vegetables and fruits. Quercetin could ameliorate colitis in mice by inducing anti-inflammatory effects of macrophages and could restore hemostasis of the microbiota in colitic mice [151]. This interesting approach should be further studied.

A further herbal treatment consisting of myrrh, chamomile blossom extract, and coffeae carbo was studied in a randomized double-blind trial in quiescent UC patients compared to mesalamine [152]. The relapse rates after 12 months did not differ between the 2 groups, rendering the German Society for Digestive and Metabolic Diseases to advocate its use as complementary treatment in UC maintenance therapy [153].

Curcumin, a polyphenol derived from the Indian spice turmeric (Curcuma longa), is used in traditional Chinese medicine and in ayurvedic medicine because of its antiinflammatory and antioxidative properties [154, 155]. In a randomized, placebo-controlled, double-blind study, curcumin in a dose of $3 \mathrm{~g}$ daily was more effective than placebo in inducing clinical remission and response in mild to moderately active UC despite maximal mesalamine treatment ( 53.8 vs. $0 \%, p=0.01$ and 65.3 vs. $12.5 \%$, $p<0.001$, respectively) [156]. All patients continued their optimal mesalamine medication. The study has been criticized for not adequately being blinded because of the potential smell and taste of curcumin [157]. Besides an effect in inducing remission, curcumin has been shown, even in a lower dose of $2 \mathrm{~g}$ daily, to maintain patients with quiescent UC in remission [158]. In this randomized, doubleblind, placebo-controlled trial, only $4.7 \%$ patients who received curcumin relapsed during 6 months of therapy compared to $20.5 \%$ in the placebo group $(p=0.04)$. There were no serious side effects. Furthermore, curcumin may be effective as enema in UC patients. In a pilot study, patients receiving curcumin enema had higher clinical response ( 92.9 vs. $50 \%, p=0.01)$ and were significantly more in remission $(71.4$ vs. $31.3 \%, p=0.03)$ than patients receiving placebo enemas (significant only in the perprotocol analysis). A Cochrane analysis supports the finding that curcumin is effective in the maintenance of remission in UC [159].

For the daily use of curcumin, 2 important facts have to be mentioned. First, the acceptable daily intake evaluated by the FAO/WHO Expert Committee on Food Additives (JEFCA) [160] is $0-3 \mathrm{mg} / \mathrm{kg}$ bodyweight, being considerably lower than the doses used in the studies. Second, due to the fact that curcumin is not labeled as a medication and only available as over-the-counter food supplement, it is often not available in pure forms and contains numerous additives. Those capsules frequently available represent turmeric capsules with around $50 \mathrm{mg}$ of curcumin and piperine, which will enhance serum concentration of curcumin [161]. This makes it very difficult to achieve the high doses used in the studies.

Plantago ovate (Psyllium) is a dietary fiber indigenous to Mediterranean region and India and used as herbal medicine [162]. In an open-label trial with 105 UC patients in remission, subjects were randomized in groups receiving Plantago ovata seeds (10 g b.i.d.), mesalamine (500 mg i.d.), or Plantago ovate seeds plus mesalamine [163]. There was no difference in maintenance of remission between the groups, so that the authors concluded that Plantago ovata might be as effective as mesalamine to maintain remission in UC. Furthermore, the fecal butyrate level was significantly increased in patients who received Plantago ovata.

\section{Malnutrition}

Patients with active IBD are at an increased risk of malnutrition. The prevalence of malnutrition in IBD ranges between 6 and 16\%, representing a 5 -fold increase in risk for malnutrition as compared to non-IBD subjects [164, 16]. Regardless of the proper definition used for malnutrition, the high prevalence calls for a more profound consideration of this complication among healthcare professionals. Unjustified bowel rest during hospitalization may further worsen the situation in UC patients [165]. History of surgery due to IBD doubles the risk for malnutrition, while ongoing clinical activity and avoidance of some food groups during a flare is associated with 
a 4- and even 10-fold higher malnutrition risk, respectively [16]. Therefore, the highest impact on malnutrition probably is derived by food-restrictive behavior and decreased appetite during flare.

The most common micronutrient deficiencies in descending order are iron, vitamin $\mathrm{D}$, vitamin B12, zinc, and folic acid deficiency. Cause of micronutrient deficiencies are multifactorial and include a restricted food intake, enteric loss of vitamins, malabsorption, and undesirable effects of some medication [166].

\section{Iron Deficiency}

Prevalence of iron deficiency (ID) can be seen in up to $70 \%$ and is the most common reason for anemia in IBD patients (ID anemia [IDA]). The second most common cause of anemia in IBD patients is anemia of chronic disease (ACD) and often co-exists in IBD patients with ID. ID in IBD patients is multifactorial and results from a decreased intake of iron, an impaired iron uptake in the duodenum and upper jejunum, decreased iron resorption due to high hepcidin levels, and chronic blood loss from the inflamed mucosa [167]. Furthermore, in CD, low BMI and nonsmoker are positively associated with IDA [168].

Diagnosing IDA in IBD patients can be difficult due to the overlap of ACD in many patients. Normally, a ferritin $<30 \mu \mathrm{g} / \mathrm{L}$ is unequivocally diagnostic for an ID, whether with or without anemia. As ferritin acts as an acute-phase reactant in inflammatory states, as well as in obesity, age, and liver disorders, ferritin level rise and can therefore mask ID. However, ferritin levels $>100 \mu \mathrm{g} / \mathrm{L}$ exclude an ID even in states of inflammation $[169,170]$. In cases of ferritin values between 30 and $100 \mu \mathrm{g} / \mathrm{L}$ with elevated CRP, transferrin saturation can be measured. A transferrin saturation $<20 \%$ implies an absolute or functional ID. Absolute ID is defined as transferrin saturation $<20 \%$ with a ferritin $<100 \mu \mathrm{g} / \mathrm{L}$ and functional ID (major component of ACD) as transferrin saturation $<20 \%$ in combination with ferritin concentrations of 100-299 $\mu \mathrm{g} / \mathrm{L}[171,172]$.

In treating iron-deficient IBD patients, some aspects have to be considered. The well-known Ganzoni formula underestimates iron requirement in IBD patients, why a new simplified and more accurate dosage scheme for IBD was evolved (FERGIcor) [173].

The widely used oral iron supplements consist of iron salts (iron sulfate, fumarate, and gluconate), and the absorption of nonheme iron is poor. The duodenum can maximally absorb 10-20 mg of iron per day and around $90 \%$ is not absorbed [174]. Therefore, high doses are often administered, what may lead to ROS-mediated toxicity of nonabsorbed iron on intestinal mucosa [175]. Further- more, oral iron can reduce Lactobacillus and Bifidobacterium bacteria and increase abundance of Enterobacteriacea [176] and subsequently lead to gut dysbiosis and increase inflammation and diarrhea $[177,178]$. Other small studies confirmed the potential of an increased clinical disease activity in IBD patients after oral ferrous fumarate [179] and a small, but in our opinion, a relevant chance of having a relapse of $6 \%$ [180].

Due to the abovementioned concerns and high rates of gastrointestinal intolerability to oral ferrous iron, a novel oral iron comprising a stable complex of ferric iron with maltol, namely, ferric maltol, has been tested in IBD patients in a Phase 3 trial [181]. The Phase 3 extension trial confirmed the tolerability of ferric maltol [182].

Nevertheless, oral iron cannot be completely abandoned in IBD patients, but it has to be kept in mind that high doses of oral iron should be avoided in IBD patients, especially in some general vitamin supplements. If given orally, iron should be administered on alternate days in low single doses to optimize iron absorption [183].

Due to high hepcidin level resulting from inflammation [184], oral resorption of iron may be severely hindered or even be impossible in active IBD patients. Therefore, ECCO recommends intravenous iron in clinically active patients, in patients with intolerance to oral iron, or those in need of erythropoiesis-stimulating agents and in case of hemoglobin levels below $10 \mathrm{~g} / \mathrm{dL}$ (due to much faster response of intravenous iron) [185].

Administration of intravenous iron may increase the risk of infection to around 33\% compared to oral or no iron [186]. Therefore, in patients with ongoing infection, intravenous iron therapy should be only given after careful risk versus benefit consideration due to a fear of exacerbating the infection [187].

After correction of ID, every patient should control iron levels every 3 months for at least 1 year, and if ferritin drops below $100 \mu \mathrm{g} / \mathrm{L}$, iron should be substituted [185]. Patients with active disease should be screened every 3 months and patients in clinical remission every 12 months regardless of anemia or not [188].

\section{Vitamin B12 Deficiency}

The prevalence of vitamin B12 ranges between 6 and $38 \%$ [189] due to different diagnostic methods used. A true vitamin B12 deficiency in asymptomatic patients is defined as a serum cobalamin $<148 \mathrm{pmol} / \mathrm{L}(200 \mathrm{ng} / \mathrm{L})$ and an elevated serum homocystein or methylmalonic acid [190]. In the duodenum, dietary cobalamin binds intrinsic factor, synthesized by the parietal cells, for its absorption in the terminal ileum [191]. Since CD can affect 
the entire gastrointestinal tract, a vitamin B12 deficiency is much more frequent in CD than in UC patients [168]. The main risk factor for vitamin B12 deficiency is an ileal resection $>30 \mathrm{~cm}$ [189]. Interestingly, despite being the main site of cobalamin absorption, an ileal CD is not a risk factor for a cobalamin deficiency [189]. A well-conducted prospective observational study in which besides cobalamin also methylmalonic acid was measured could demonstrate that a true vitamin B12 deficiency is very rare (3\% in CD and 3.3\% in UC). Normally, UC patients have a vitamin B12 deficiency in a similar frequency as the general population. An exception is UC patients with ileo-anal J-pouch that may suffer of a vitamin B12 deficiency, probably due a small bacterial overgrowth [192]. Anecdotally, after many years of backwash ileitis, a vitamin B12 deficiency could result. However, this has never been investigated.

\section{Vitamin D Deficiency}

Up to $60 \%$ of IBD patients have a vitamin D deficiency, especially patients diagnosed with CD and an increased disease activity $[72,193,194]$ or pregnant women with IBD [195]. Interestingly, young male patients have a very high risk [141] and CD patients with isolated colonic involvement or UC patients had a similar prevalence of $25(\mathrm{OH}) \mathrm{D}$ levels compared to CD patients with ileocolonic or small bowel disease [141]. Additionally, a meta-analysis could demonstrate a higher prevalence of vitamin D deficiency in patients with IBD compared to healthy patients [196]. The underlying reasons for vitamin D deficiency in IBD are multifactorial. There are 2 natural sources of vitamin $\mathrm{D}$, namely, ergocalciferol (vitamin D2), being present in food, especially in fatty fish and mushrooms, and vitamin D3 synthesized in the epidermis of the skin upon UVB irradiation [197]. Since in most northern countries vitamin $\mathrm{D}$ deficiency is a common problem in the general population, malabsorption of vitamin $\mathrm{D}$ is probably not a major causative factor for the vitamin $\mathrm{D}$ deficiency in IBD. Rather, patients with IBD have an insufficient exposure of sun and the inflammation upregulates cytokines that subsequently reduce the serum 25(OH)D level [197].

Although the data regarding a potential benefit for the course of disease in IBD are inconclusive, vitamin D is important to bone health. Especially in patients with IBD, who probably needs repetitively corticosteroids, low $25(\mathrm{OH}) \mathrm{D}$ levels should be avoided. Since adherence is an important limitation in patients with chronic diseases, a practical approach to substitute vitamin $\mathrm{D}$ is giving them 1 monthly 45,000 IU.

Nutrition in IBD

\section{Zinc Deficiency}

Zinc is a trace element found in high amounts in food of animal origin, especially in oysters and beef [198]. It is not surprising that vegetarian have much more often a zinc deficiency than omnivores [199]. Due to the fact that zinc is absorbed in the small intestine and the main route of zinc losses are endogenous intestinal losses with up to $12 \mathrm{mg}$ zinc loss in patients with a stoma [200, 201], patients with malabsorption are prone to zinc deficiency. In a Korean study, zinc deficiency could be demonstrated in $38.5 \%$ of IBD patients [202]. Likewise, around $65 \%$ of CD patients in remission were found to have zinc levels below the reference value despite a higher intake than the controls [203]. In children with CD, zinc deficiency is not very frequent but higher than in the healthy controls [204]. The low zinc values are associated with an increased risk for hospitalization, surgery, and complication in CD and UC [205], and normalization of zinc deficiency was associated with these outcomes [205]. Although low zinc levels did not predict a complicated disease course in the Swiss IBD Cohort, it was associated with depressive symptoms in multivariate analysis [206]. However, serum zinc levels are notoriously difficult to interpret because inflammation, collection time during the day, age, and sex may influence zinc concentration [207]. Therefore, it is debatable if serum or plasma zinc values represent zinc status adequately [200, 208]. Nevertheless, despite its inaccuracy, plasma zinc level is probably nowadays the best indicator measuring zinc status [209]. Another way to asses zinc status would be clinically, whereas the clinical syndrome of acrodermatitis enteropathica with red, desquamating lesions on the hands and the nasolabial folds together with hair loss is pathognomonic for zinc deficiency [208].

As zinc interferes with the intestinal absorption of iron, especially copper, oral supplementation should not be carried out for longer than 2-3 weeks [210, 211].

\section{Conclusion}

Western lifestyle, specifically western diet, is a major driving factor for the increased prevalence of IBD in industrialized and emerging countries. Increased intake of fats and/or proteins, reduced intake of fruits and vegetables, as well as the increase in the use of emulsifiers or other binding substances are among the most important candidate factors to promote inflammation in the intestines of healthy subjects. However, as of today it remains unclear which of these individual nutritional factors are

Digestion 2020;101(suppl 1):120-135 129 
primarily responsible for the recent epidemiological increase in IBD.

Although there are countless books and websites on nutrition and IBD, there is little evidence to support restrictive dietary interventions in patients with IBD. Therefore, current recommendations to our patients should center around and encourage a healthy and balanced diet based on unprocessed foods instead of restriction and/or supplementation of specific dietary components.

\section{Acknowledgment}

None.

\section{Disclosure Statement}

The authors have no conflicts of interest to declare.

\section{Funding Sources}

There are no funding sources to declare.

\section{Author Contributions}

P.S. conception and design of the study, drafting the article, approved the final version. M.M.-G., D.S., S.R.V., and H.T. design of the study, critical revision, and approved the final version. L.B. concept and design of the study, critical revision, and approved the final version.

\section{References}

1 Shaw SY, Blanchard JF, Bernstein CN. Association between the use of antibiotics and new diagnoses of Crohn's disease and ulcerative colitis. Am J Gastroenterol. 2011 Dec;106(12): 2133-42.

2 Godet PG, May GR, Sutherland LR. Metaanalysis of the role of oral contraceptive agents in inflammatory bowel disease. Gut. 1995 Nov;37(5):668-73.

3 Cornish JA, Tan E, Simillis C, Clark SK, Teare J, Tekkis PP. The risk of oral contraceptives in the etiology of inflammatory bowel disease: a meta-analysis. Am J Gastroenterol. 2008 Sep; 103(9):2394-400.

4 Khalili H, Higuchi LM, Ananthakrishnan AN, Richter JM, Feskanich D, Fuchs CS, et al. Oral contraceptives, reproductive factors and risk of inflammatory bowel disease. Gut. 2013 Aug;62(8):1153-9.

5 Soon IS, Molodecky NA, Rabi DM, Ghali WA, Barkema HW, Kaplan GG. The relationship between urban environment and the inflammatory bowel diseases: a systematic review and meta-analysis. BMC Gastroenterol. 2012 May; 12(1):51.

6 Ng SC, Kaplan GG, Tang W, Banerjee R, Adigopula B, Underwood FE, et al. Population density and risk of inflammatory bowel disease: A prospective population-based study in 13 countries or regions in asia-pacific. Am J Gastroenterol. 2019 Jan;114(1):107-15.

7 Bernstein CN, Shanahan F. Disorders of a modern lifestyle: reconciling the epidemiology of inflammatory bowel diseases. Gut. 2008 Sep;57(9):1185-91.

8 Ng SC, Bernstein CN, Vatn MH, Lakatos PL, Loftus EV Jr, Tysk C, et al.; Epidemiology and Natural History Task Force of the International Organization of Inflammatory Bowel Disease (IOIBD). Geographical variability and environmental risk factors in inflammatory bowel disease. Gut. 2013 Apr;62(4):630-49.
9 Rogler G, Vavricka S. Exposome in IBD: recent insights in environmental factors that influence the onset and course of IBD. Inflamm Bowel Dis. 2015 Feb;21(2):400-8.

10 Khalili H, Chan SS, Lochhead P, Ananthakrishnan AN, Hart AR, Chan AT. The role of diet in the aetiopathogenesis of inflammatory bowel disease. Nat Rev Gastroenterol Hepatol. 2018 Sep;15(9):525-35.

11 Forbes A, Escher J, Hébuterne X, Kłęk S, Krznaric Z, Schneider S, et al. ESPEN guideline: clinical nutrition in inflammatory bowel disease. Clin Nutr. 2017 Apr;36(2):321-47.

12 Kornbluth A, Sachar DB; Practice Parameters Committee of the American College of Gastroenterology. Practice Parameters Committee of the American College of G: Ulcerative colitis practice guidelines in adults: American college of gastroenterology, practice parameters committee. Am J Gastroenterol. 2010 Mar;105(3):501-23.

13 Gomollón F, Dignass A, Annese V, Tilg H, Van Assche G, Lindsay JO, et al.; ECCO. 3rd European Evidence-based Consensus on the Diagnosis and Management of Crohn's Disease 2016: Part 1: Diagnosis and Medical Management. J Crohn's Colitis. 2017 Jan;11(1):325.

14 Harbord M, Eliakim R, Bettenworth D, Karmiris K, Katsanos K, Kopylov U, et al.; European Crohn's and Colitis Organisation [ECCO]. Third European Evidence-based Consensus on Diagnosis and Management of Ulcerative Colitis. Part 2: Current Management. J Crohn's Colitis. 2017 Jul;11(7):76984.

15 Holt DQ, Strauss BJ, Moore GT. Patients with inflammatory bowel disease and their treating clinicians have different views regarding diet. J Hum Nutr Diet. 2017 Feb;30(1):66-72.

16 Casanova MJ, Chaparro M, Molina B, Merino O, Batanero R, Dueñas-Sadornil C, et al. Prev- alence of malnutrition and nutritional characteristics of patients with inflammatory bowel disease. J Crohn's Colitis. 2017 Dec;11(12): 1430-9.

17 Zallot C, Quilliot D, Chevaux JB, Peyrin-Biroulet $\mathrm{C}$, Guéant-Rodriguez RM, Freling E, et al. Dietary beliefs and behavior among inflammatory bowel disease patients. Inflamm Bowel Dis. 2013 Jan;19(1):66-72.

18 Wong S, Walker JR, Carr R, Graff LA, Clara I, Promislow S, et al. The information needs and preferences of persons with longstanding inflammatory bowel disease. Can J Gastroenterol. 2012 Aug;26(8):525-31.

19 Limdi JK, Aggarwal D, McLaughlin JT. Dietary practices and beliefs in patients with inflammatory bowel disease. Inflamm Bowel Dis. 2016 Jan;22(1):164-70.

20 de Vries JH, Dijkhuizen M, Tap P, Witteman BJ. Patient's dietary beliefs and behaviours in inflammatory bowel disease. Dig Dis. 2019; 37(2):131-9.

21 Cohen AB, Lee D, Long MD, Kappelman MD, Martin CF, Sandler RS, et al. Dietary patterns and self-reported associations of diet with symptoms of inflammatory bowel disease. Dig Dis Sci. 2013 May;58(5):1322-8.

22 Vagianos K, Clara I, Carr R, Graff LA, Walker JR, Targownik LE, et al. What are adults with inflammatory bowel disease (ibd) eating? A closer look at the dietary habits of a population-based canadian ibd cohort. JPEN J Parenter Enteral Nutr. 2016 Mar;40(3):40511.

23 Owczarek D, Rodacki T, Domagała-Rodacka R, Cibor D, Mach T. Diet and nutritional factors in inflammatory bowel diseases. World J Gastroenterol. 2016 Jan;22(3):895-905.

24 Bergeron F, Bouin M, D'Aoust L, Lemoyne M, Presse N. Food avoidance in patients with inflammatory bowel disease: What, when and who? Clin Nutr. 2018 Jun;37(3):884-9. 
25 Ng SC, Shi HY, Hamidi N, Underwood FE, Tang W, Benchimol EI, et al. Worldwide incidence and prevalence of inflammatory bowel disease in the 21st century: a systematic review of population-based studies. Lancet. 2018 Dec;390(10114):2769-78.

26 Lee JC, Biasci D, Roberts R, Gearry RB, Mansfield JC, Ahmad T, et al.; UK IBD Genetics Consortium. Genome-wide association study identifies distinct genetic contributions to prognosis and susceptibility in Crohn's disease. Nat Genet. 2017 Feb;49(2):262-8.

27 Ananthakrishnan AN, Bernstein CN, Iliopoulos D, Macpherson A, Neurath MF, Ali RA, et al. Environmental triggers in IBD: a review of progress and evidence. Nat Rev Gastroenterol Hepatol. 2018 Jan;15(1):39-49.

28 David LA, Maurice CF, Carmody RN, Gootenberg DB, Button JE, Wolfe BE, et al. Diet rapidly and reproducibly alters the human gut microbiome. Nature. 2014 Jan;505(7484): 559-63.

29 Wu GD, Chen J, Hoffmann C, Bittinger K, Chen YY, Keilbaugh SA, et al. Linking longterm dietary patterns with gut microbial enterotypes. Science. 2011 Oct;334(6052):1058.

30 Turnbaugh PJ, Ridaura VK, Faith JJ, Rey FE, Knight R, Gordon JI. The effect of diet on the human gut microbiome: a metagenomic analysis in humanized gnotobiotic mice. Sci Transl Med. 2009 Nov;1(6):6ra14.

31 Gupta VK, Paul S, Dutta C. Geography, ethnicity or subsistence-specific variations in human microbiome composition and diversity. Front Microbiol. 2017 Jun;8:1162.

32 De Filippo C, Cavalieri D, Di Paola M, Ramazzotti M, Poullet JB, Massart S, et al. Impact of diet in shaping gut microbiota revealed by a comparative study in children from Europe and rural Africa. Proc Natl Acad Sci USA. 2010 Aug;107(33):14691-6.

33 Ruengsomwong S, Korenori Y, Sakamoto N, Wannissorn B, Nakayama J, Nitisinprasert S. Senior Thai fecal microbiota comparison between vegetarians and non-vegetarians using PCR-DGGE and real-time PCR. J Microbiol Biotechnol. 2014 Aug;24(8):1026-33.

34 Schulfer AF, Battaglia T, Alvarez Y, Bijnens L, Ruiz VE, Ho M, et al. Intergenerational transfer of antibiotic-perturbed microbiota enhances colitis in susceptible mice. Nat Microbiol. 2018 Feb;3(2):234-42.

35 Ott SJ, Schreiber S. Reduced microbial diversity in inflammatory bowel diseases. Gut. 2006 Aug;55(8):1207.

36 Walker AW, Sanderson JD, Churcher C, Parkes GC, Hudspith BN, Rayment N, et al. High-throughput clone library analysis of the mucosa-associated microbiota reveals dysbiosis and differences between inflamed and non-inflamed regions of the intestine in inflammatory bowel disease. BMC Microbiol. $2011 \mathrm{Jan} ; 11(1): 7$.

37 Martinez-Medina M, Aldeguer X, Lopez-Siles M, González-Huix F, López-Oliu C, Dahbi G, et al. Molecular diversity of Escherichia coli in the human gut: new ecological evidence supporting the role of adherent-invasive E. coli (AIEC) in Crohn's disease. Inflamm Bowel Dis. 2009 Jun;15(6):872-82.

38 Seksik P, Rigottier-Gois L, Gramet G, Sutren M, Pochart P, Marteau P, et al. Alterations of the dominant faecal bacterial groups in patients with Crohn's disease of the colon. Gut. 2003 Feb;52(2):237-42.

39 Levine A, Sigall Boneh R, Wine E. Evolving role of diet in the pathogenesis and treatment of inflammatory bowel diseases. Gut. 2018 Sep;67(9):1726-38.

40 Martinez-Medina M, Denizot J, Dreux N, Robin F, Billard E, Bonnet R, et al. Western diet induces dysbiosis with increased $\mathrm{E}$ coli in CEABAC10 mice, alters host barrier function favouring AIEC colonisation. Gut. 2014 Jan; 63(1):116-24.

41 Chassaing B, Van de Wiele T, De Bodt J, Marzorati M, Gewirtz AT. Dietary emulsifiers directly alter human microbiota composition and gene expression ex vivo potentiating intestinal inflammation. Gut. 2017 Aug;66(8): 1414-27.

42 Ho NT, Li F, Lee-Sarwar KA, Tun HM, Brown BP, Pannaraj PS, et al. Meta-analysis of effects of exclusive breastfeeding on infant gut microbiota across populations. Nat Commun. 2018 Oct; $9(1): 4169$.

43 Victora CG, Bahl R, Barros AJ, França GV, Horton S, Krasevec J, et al.; Lancet Breastfeeding Series Group. Breastfeeding in the 21st century: epidemiology, mechanisms, and lifelong effect. Lancet. 2016 Jan;387(10017):47590.

44 Klement E, Cohen RV, Boxman J, Joseph A, Reif S. Breastfeeding and risk of inflammatory bowel disease: a systematic review with metaanalysis. Am J Clin Nutr. 2004 Nov;80(5): 1342-52.

45 Barclay AR, Russell RK, Wilson ML, Gilmour WH, Satsangi J, Wilson DC. Systematic review: the role of breastfeeding in the development of pediatric inflammatory bowel disease. J Pediatr. 2009 Sep;155(3):421-6.

$46 \mathrm{Xu} \mathrm{L}$, Lochhead P, Ko Y, Claggett B, Leong RW, Ananthakrishnan AN. Systematic review with meta-analysis: breastfeeding and the risk of Crohn's disease and ulcerative colitis. Aliment Pharmacol Ther. 2017 Nov;46(9): 780-9.

47 Lindoso L, Mondal K, Venkateswaran S, Somineni HK, Ballengee $C$, Walters TD, et al. The effect of early-life environmental exposures on disease phenotype and clinical course of crohn's disease in children. Am J Gastroenterol. 2018 Oct;113(10):1524-9.

48 Patterson E, Wall R, Fitzgerald GF, Ross RP, Stanton C. Health implications of high dietary omega-6 polyunsaturated Fatty acids. J Nutr Metab. 2012;2012:539426.

49 Simopoulos AP. The importance of the ratio of omega-6/omega-3 essential fatty acids. Biomed Pharmacother. 2002 Oct;56(8):365-79.

50 Shoda R, Matsueda K, Yamato S, Umeda N. Epidemiologic analysis of Crohn disease in Ja- pan: increased dietary intake of $n-6$ polyunsaturated fatty acids and animal protein relates to the increased incidence of Crohn disease in Japan. Am J Clin Nutr. 1996 May;63(5):741-5.

51 IBD in EPIC Study Investigators, Tjonneland A, Overvad K, Bergmann MM, Nagel G, Linseisen J, Hallmans G, et al. Linoleic acid, a dietary n- 6 polyunsaturated fatty acid, and the aetiology of ulcerative colitis: A nested casecontrol study within a european prospective cohort study. Gut. 2009 Dec;58(12):1606-11.

52 Amre DK, D'Souza S, Morgan K, Seidman G, Lambrette P, Grimard G, et al. Imbalances in dietary consumption of fatty acids, vegetables, and fruits are associated with risk for Crohn's disease in children. Am J Gastroenterol. 2007 Sep;102(9):2016-25.

53 John S, Luben R, Shrestha SS, Welch A, Khaw KT, Hart AR. Dietary n-3 polyunsaturated fatty acids and the aetiology of ulcerative colitis: a UK prospective cohort study. Eur J Gastroenterol Hepatol. 2010 May;22(5):602-6.

54 Ananthakrishnan AN, Khalili $\mathrm{H}$, Konijeti GG, Higuchi LM, de Silva P, Fuchs CS, et al. Long-term intake of dietary fat and risk of ulcerative colitis and Crohn's disease. Gut. 2014 May;63(5):776-84.

55 Wang F, Lin X, Zhao Q, Li J. Fat intake and risk of ulcerative colitis: systematic review and dose-response meta-analysis of epidemiological studies. J Gastroenterol Hepatol. 2017 Jan;32(1):19-27.

56 Sakamoto N, Kono S, Wakai K, Fukuda Y, Satomi M, Shimoyama T, et al.; Epidemiology Group of the Research Committee on Inflammatory Bowel Disease in Japan. Dietary risk factors for inflammatory bowel disease: a multicenter case-control study in Japan. Inflamm Bowel Dis. 2005 Feb;11(2):154-63.

57 Farrukh A, Mayberry JF. Is there a role for fish oil in inflammatory bowel disease? World J Clin Cases. 2014 Jul;2(7):250-2.

58 Ananthakrishnan AN, Khalili H, Song M, Higuchi LM, Lochhead P, Richter JM, et al. Genetic polymorphisms in fatty acid metabolism modify the association between dietary $\mathrm{n} 3$ : N6 intake and risk of ulcerative colitis: A prospective cohort study. Inflamm Bowel Dis. 2017 Nov;23(11):1898-904.

59 Jantchou P, Morois S, Clavel-Chapelon F, Boutron-Ruault MC, Carbonnel F. Animal protein intake and risk of inflammatory bowel disease: the E3N prospective study. Am J Gastroenterol. 2010 Oct;105(10):2195-201.

60 Hou JK, Abraham B, El-Serag H. Dietary intake and risk of developing inflammatory bowel disease: a systematic review of the literature. Am J Gastroenterol. 2011 Apr;106(4): 563-73.

61 Ge J, Han TJ, Liu J, Li JS, Zhang XH, Wang Y, et al. Meat intake and risk of inflammatory bowel disease: A meta-analysis. Turk J Gastroenterol. 2015 Nov;26(6):492-7.

62 Reif S, Klein I, Lubin F, Farbstein M, Hallak A, Gilat T. Pre-illness dietary factors in inflammatory bowel disease. Gut. 1997 Jun;40(6): 754-60. 
63 Wang F, Feng J, Gao Q, Ma M, Lin X, Liu J, et al. Carbohydrate and protein intake and risk of ulcerative colitis: systematic review and dose-response meta-analysis of epidemiological studies. Clin Nutr. 2017 Oct;36(5):125965.

64 Chan SS, Luben R, van Schaik F, Oldenburg B, Bueno-de-Mesquita HB, Hallmans G, et al. Carbohydrate intake in the etiology of Crohn's disease and ulcerative colitis. Inflamm Bowel Dis. 2014 Nov;20(11):2013-21.

65 Racine A, Carbonnel F, Chan SS, Hart AR, Bueno-de-Mesquita HB, Oldenburg B, et al. Dietary patterns and risk of inflammatory bowel disease in europe: results from the epic study. Inflamm Bowel Dis. 2016 Feb;22(2): 345-54.

66 Khalili H, Hakansson N, Chan SS, Ludvigsson JF, Olen O, Chan AT, et al. No association between consumption of sweetened beverages and risk of later-onset crohn's disease or ulcerative colitis. Clin Gastroenterol Hepatol. 2019 Jan; 17(1):123-129.

67 Li F, Liu X, Wang W, Zhang D. Consumption of vegetables and fruit and the risk of inflammatory bowel disease: a meta-analysis. Eur $\mathrm{J}$ Gastroenterol Hepatol. 2015 Jun;27(6):62330.

68 Ananthakrishnan AN, Khalili $\mathrm{H}$, Konijeti GG, Higuchi LM, de Silva P, Korzenik JR, et al. A prospective study of long-term intake of dietary fiber and risk of Crohn's disease and ulcerative colitis. Gastroenterology. 2013 Nov; 145(5):970-7.

69 Liu X, Wu Y, Li F, Zhang D. Dietary fiber intake reduces risk of inflammatory bowel disease: result from a meta-analysis. Nutr Res. 2015 Sep;35(9):753-8.

70 Ananthakrishnan AN, Khalili H, Song M, Higuchi LM, Richter JM, Nimptsch K, et al. High school diet and risk of crohn's disease and ulcerative colitis. Inflamm Bowel Dis. 2015 Oct; 21(10):2311-9.

71 Andersen V, Chan S, Luben R, Khaw KT, Olsen $\mathrm{A}$, Tjonneland $\mathrm{A}$, et al. Fibre intake and the development of inflammatory bowel disease: A European prospective multi-centre cohort study (EPIC-IBD). J Crohn's Colitis. 2018 Jan;12(2):129-36.

72 Caviezel D, Maissen S, Niess JH, Kiss C, Hruz P. High prevalence of vitamin d deficiency among patients with inflammatory bowel disease. Inflamm Intest Dis. 2018 Jul;2(4):20010.

73 Ananthakrishnan AN, Khalili H, Higuchi LM, Bao Y, Korzenik JR, Giovannucci EL, et al. Higher predicted vitamin D status is associated with reduced risk of Crohn's disease. Gastroenterology. 2012 Mar; 142(3): 482-9.

74 Opstelten JL, Chan SS, Hart AR, van Schaik FD, Siersema PD, Lentjes EG, et al. Prediagnostic serum vitamin d levels and the risk of crohn's disease and ulcerative colitis in european populations: A nested case-control study. Inflamm Bowel Dis. 2018 Feb;24(3): 633-40.
75 Lu Y, Zamora-Ros R, Chan S, Cross AJ, Ward $\mathrm{H}$, Jakszyn P, et al. Dietary polyphenols in the aetiology of crohn's disease and ulcerative colitis-a multicenter european prospective cohort study (epic). Inflamm Bowel Dis. 2017 Dec;23(12):2072-82.

76 D'Souza S, Levy E, Mack D, Israel D, Lambrette P, Ghadirian P, et al. Dietary patterns and risk for Crohn's disease in children. Inflamm Bowel Dis. 2008 Mar;14(3):367-73.

77 Limketkai BN, Iheozor-Ejiofor Z, GjuladinHellon T, Parian A, Matarese LE, Bracewell K, et al. Dietary interventions for induction and maintenance of remission in inflammatory bowel disease. Cochrane Database Syst Rev. 2019 Feb;2:CD012839.

78 Cima RR, Anderson KJ, Larson DW, Dozois EJ, Hassan I, Sandborn WJ, et al. Internet use by patients in an inflammatory bowel disease specialty clinic. Inflamm Bowel Dis. 2007 Oct; 13(10): 1266-70.

79 Jowett SL, Seal CJ, Phillips E, Gregory W, Barton JR, Welfare MR. Dietary beliefs of people with ulcerative colitis and their effect on relapse and nutrient intake. Clin Nutr. 2004 Apr;23(2):161-70.

80 Lewis JD. The role of diet in inflammatory bowel disease. Gastroenterol Hepatol (N Y). 2016 Jan;12(1):51-3.

81 Narula N, Dhillon A, Zhang D, Sherlock ME, Tondeur M, Zachos M. Enteral nutritional therapy for induction of remission in Crohn's disease. Cochrane Database Syst Rev. 2018 Apr;4:CD000542.

82 Zachos M, Tondeur M, Griffiths AM. Enteral nutritional therapy for induction of remission in Crohn's disease. Cochrane Database Syst Rev. 2007 Jan;(1):CD000542.

83 Borrelli O, Cordischi L, Cirulli M, Paganelli M, Labalestra V, Uccini S, et al. Polymeric diet alone versus corticosteroids in the treatment of active pediatric crohn's disease: A randomized controlled open-label trial. Clin Gastroenterol Hepatol. 2006 Jun;4(6):744-53.

84 Rubio A, Pigneur B, Garnier-Lengliné H, Talbotec C, Schmitz J, Canioni D, et al. The efficacy of exclusive nutritional therapy in paediatric Crohn's disease, comparing fractionated oral vs. continuous enteral feeding. Aliment Pharmacol Ther. 2011 Jun;33(12):1332-9.

85 Grover Z, Muir R, Lewindon P. Exclusive enteral nutrition induces early clinical, mucosal and transmural remission in paediatric Crohn's disease. J Gastroenterol. 2014 Apr; 49(4):638-45

86 Pigneur B, Lepage P, Mondot S, Schmitz J, Goulet O, Dore J, et al. Mucosal Healing and Bacterial Composition in Response to Enteral Nutrition Vs Steroid-based Induction Therapy-A Randomised Prospective Clinical Trial in Children With Crohn's Disease. J Crohns Colitis. 2019 Jul 25;13(7):846-55.

87 Ruemmele FM, Veres G, Kolho KL, Griffiths A, Levine A, Escher JC, et al.; European Crohn's and Colitis Organisation; European Society of Pediatric Gastroenterology, Hepatology and Nutrition. Consensus guidelines of ECCO/ESPGHAN on the medical management of pediatric Crohn's disease. J Crohn's Colitis. 2014;8(10):1179-207.

88 Matsuoka K, Kobayashi T, Ueno F, Matsui T, Hirai F, Inoue N, et al. Evidence-based clinical practice guidelines for inflammatory bowel disease. J Gastroenterol. 2018 Mar;53(3):30553.

89 Okada M, Yao T, Yamamoto T, Takenaka K, Imamura $\mathrm{K}$, Maeda $\mathrm{K}$, et al. Controlled trial comparing an elemental diet with prednisolone in the treatment of active Crohn's disease. Hepatogastroenterology. 1990 Feb; 37(1):72-80.

90 Johnson T, Macdonald S, Hill SM, Thomas A, Murphy MS. Treatment of active Crohn's disease in children using partial enteral nutrition with liquid formula: a randomised controlled trial. Gut. 2006 Mar;55(3):356-61.

91 Akobeng AK, Zhang D, Gordon M, MacDonald JK. Enteral nutrition for maintenance of remission in Crohn's disease. Cochrane Database Syst Rev. 2018 Aug;8:CD005984.

92 Takagi S, Utsunomiya K, Kuriyama S, Yokoyama $\mathrm{H}$, Takahashi S, Iwabuchi M, et al. Effectiveness of an 'half elemental diet' as maintenance therapy for Crohn's disease: A randomized-controlled trial. Aliment Pharmacol Ther. 2006 Nov;24(9):1333-40.

93 Sigall-Boneh R, Pfeffer-Gik T, Segal I, Zangen T, Boaz M, Levine A. Partial enteral nutrition with a Crohn's disease exclusion diet is effective for induction of remission in children and young adults with Crohn's disease. Inflamm Bowel Dis. 2014 Aug;20(8):1353-60.

94 Sigall Boneh R, Sarbagili Shabat C, Yanai H, Chermesh I, Ben Avraham S, Boaz M, et al. Dietary therapy with the crohn's disease exclusion diet is a successful strategy for induction of remission in children and adults failing biological therapy. J Crohn's Colitis. 2017 Oct;11(10):1205-12.

95 Levine A, Wine E, Assa A, Sigall Boneh R, Shaoul R, Kori M, et al. Crohn's disease exclusion diet plus partial enteral nutrition induces sustained remission in a randomized controlled trial. Gastroenterology. 2019;157:44050.e8.

96 Kerr RA. Planetary science. Saturn: the unfinished symphony. Science. 2004 May; 304(5675):1230-2.

97 Svolos V, Hansen R, Nichols B, Quince C, Ijaz UZ, Papadopoulou RT, et al. Treatment of active crohn's disease with an ordinary foodbased diet that replicates exclusive enteral nutrition. Gastroenterology. 2019;156:1354-67. e1356.

98 Burgis JC, Nguyen K, Park KT, Cox K. Response to strict and liberalized specific carbohydrate diet in pediatric Crohn's disease. World J Gastroenterol. 2016 Feb;22(6):21117.

99 Cohen SA, Gold BD, Oliva S, Lewis J, Stallworth A, Koch B, et al. Clinical and mucosal improvement with specific carbohydrate diet in pediatric Crohn disease. J Pediatr Gastroenterol Nutr. 2014 Oct;59(4):516-21. 
100 Wahbeh GT, Ward BT, Lee DY, Giefer MJ, Suskind DL. Lack of mucosal healing from modified specific carbohydrate diet in pediatric patients with crohn disease. J Pediatr Gastroenterol Nutr. 2017 Sep;65(3):289-92.

101 Suskind DL, Cohen SA, Brittnacher MJ, Wahbeh G, Lee D, Shaffer ML, et al. Clinical and fecal microbial changes with diet therapy in active inflammatory bowel disease. J Clin Gastroenterol. 2018 Feb;52(2):155-63.

102 Suskind DL, Wahbeh G, Cohen SA, Damman CJ, Klein J, Braly K, et al. Patients perceive clinical benefit with the specific carbohydrate diet for inflammatory bowel disease. Dig Dis Sci. 2016 Nov;61(11):3255-60.

103 Kakodkar S, Farooqui AJ, Mikolaitis SL, Mutlu EA. The specific carbohydrate diet for inflammatory bowel disease: A case series. J Acad Nutr Diet. 2015 Aug;115(8): 1226-32.

104 Riccio P, Rossano R. Diet, gut microbiota, and vitamins $\mathrm{d}+\mathrm{a}$ in multiple sclerosis. Neurotherapeutics. 2018 Jan;15(1):75-91.

105 Schreiner P, Yilmaz B, Rossel JB, Franc Y, Misselwitz B, Scharl M, et al. Vegetarian or gluten-free diets in patients with inflammatory bowel disease are associated with lower psychological well-being and a different gut microbiota, but no beneficial effects on the course of the disease. United European Gastroenterol J. 2019 Jul;7(6):767-81.

106 Jowett SL, Seal CJ, Pearce MS, Phillips E, Gregory W, Barton JR, et al. Influence of dietary factors on the clinical course of ulcerative colitis: a prospective cohort study. Gut. 2004 Oct;53(10):1479-84.

107 Chiba M, Abe T, Tsuda H, Sugawara T, Tsuda S, Tozawa H, et al. Lifestyle-related disease in Crohn's disease: relapse prevention by a semi-vegetarian diet. World J Gastroenterol. 2010 May;16(20):2484-95.

108 Albenberg L, Brensinger CM, Wu Q, Gilroy E, Kappelman MD, Sandler RS, et al. A diet low in red and processed meat does not reduce rate of crohn's disease flares. Gastroenterology. 2019 Jul;157(1):128-136.e5.

109 Devkota S, Wang Y, Musch MW, Leone V, Fehlner-Peach H, Nadimpalli A, et al. Dietary-fat-induced taurocholic acid promotes pathobiont expansion and colitis in Il10-/mice. Nature. 2012 Jul;487(7405):104-8.

110 Barnes EL, Nestor M, Onyewadume L, de Silva PS, Korzenik JR; DREAM Investigators. High dietary intake of specific fatty acids increases risk of flares in patients with ulcerative colitis in remission during treatment with aminosalicylates. Clin Gastroenterol Hepatol. 2017 Sep;15(9):1390-6.e1.

111 Belluzzi A, Brignola C, Campieri M, Pera A, Boschi S, Miglioli M. Effect of an entericcoated fish-oil preparation on relapses in Crohn's disease. N Engl J Med. 1996 Jun; 334(24):1557-60.

112 Feagan BG, Sandborn WJ, Mittmann U, Bar-Meir S, D'Haens G, Bradette M, et al. Omega-3 free fatty acids for the maintenance of remission in Crohn disease: the
EPIC Randomized Controlled Trials. JAMA. 2008 Apr;299(14):1690-7.

113 Chapkin RS, Seo J, McMurray DN, Lupton JR. Mechanisms by which docosahexaenoic acid and related fatty acids reduce colon cancer risk and inflammatory disorders of the intestine. Chem Phys Lipids. 2008 May;153(1):14-23.

114 Turner D, Shah PS, Steinhart AH, Zlotkin S, Griffiths AM. Maintenance of remission in inflammatory bowel disease using omega-3 fatty acids (fish oil): a systematic review and meta-analyses. Inflamm Bowel Dis. 2011 Jan;17(1):336-45.

115 Llewellyn SR, Britton GJ, Contijoch EJ, Vennaro OH, Mortha A, Colombel JF, et al. Interactions between diet and the intestinal microbiota alter intestinal permeability and colitis severity in mice. Gastroenterology. 2018;154:1037-46.e32.

116 Brotherton CS, Martin CA, Long MD, Kappelman MD, Sandler RS. Avoidance of fiber is associated with greater risk of crohn's disease flare in a 6-month period. Clin Gastroenterol Hepatol. 2016 Aug;14(8):1130-6.

117 Wedlake L, Slack N, Andreyev HJ, Whelan $\mathrm{K}$. Fiber in the treatment and maintenance of inflammatory bowel disease: a systematic review of randomized controlled trials. Inflamm Bowel Dis. 2014 Mar;20(3):576-86.

118 Kanai T, Matsuoka K, Naganuma M, Hayashi A, Hisamatsu T. Diet, microbiota, and inflammatory bowel disease: lessons from Japanese foods. Korean J Intern Med (Korean Assoc Intern Med). 2014 Jul;29(4):409-15.

119 Godny L, Maharshak N, Reshef L, Goren I, Yahav L, Fliss-Isakov N, et al. Fruit consumption is associated with alterations in microbial composition and lower rates of pouchitis. J Crohns Colitis. 2019 Sep 27; 13(10):1265-72.

120 Challa HJ, Uppaluri KR. Paleolithic diet. StatPearls [Internet]. Treasure Island, FL: StatPearls Publishing; 2019.

121 Konijeti GG, Kim N, Lewis JD, Groven S, Chandrasekaran A, Grandhe S, et al. Efficacy of the autoimmune protocol diet for inflammatory bowel disease. Inflamm Bowel Dis. 2017 Nov;23(11):2054-60.

122 Olendzki BC, Silverstein TD, Persuitte GM, Ma Y, Baldwin KR, Cave D. An anti-inflammatory diet as treatment for inflammatory bowel disease: a case series report. Nutr J. $2014 \mathrm{Jan} ; 13(1): 5$.

123 Estruch R, Ros E, Salas-Salvadó J, Covas MI, Corella D, Arós F, et al.; PREDIMED Study Investigators. Primary prevention of cardiovascular disease with a mediterranean diet supplemented with extra-virgin olive oil or nuts. N Engl J Med. 2018 Jun;378(25):e34.

124 Tosti V, Bertozzi B, Fontana L. Health benefits of the mediterranean diet: metabolic and molecular mechanisms. J Gerontol A Biol Sci Med Sci. 2018 Mar;73(3):318-26.

125 Estruch R. Anti-inflammatory effects of the Mediterranean diet: the experience of the PREDIMED study. Proc Nutr Soc. 2010 Aug;69(3):333-40.
126 Marlow G, Ellett S, Ferguson IR, Zhu S, Karunasinghe $\mathrm{N}$, Jesuthasan AC, et al. Transcriptomics to study the effect of a Mediterranean-inspired diet on inflammation in Crohn's disease patients. Hum Genomics. 2013 Nov;7(1):24.

127 The effect of diet on disease activity and symptoms in patients with ulcerative colitis. Available from: https://ClinicalTrials.gov/ show/NCT03053713.

128 Halpin SJ, Ford AC. Prevalence of symptoms meeting criteria for irritable bowel syndrome in inflammatory bowel disease: systematic review and meta-analysis. Am J Gastroenterol. 2012 Oct;107(10):1474-82.

129 Gearry RB, Irving PM, Barrett JS, Nathan DM, Shepherd SJ, Gibson PR. Reduction of dietary poorly absorbed short-chain carbohydrates (FODMAPs) improves abdominal symptoms in patients with inflammatory bowel disease-a pilot study. J Crohn's Colitis. 2009 Feb;3(1):8-14.

130 Cox SR, Prince AC, Myers CE, Irving PM, Lindsay JO, Lomer MC, et al. Fermentable carbohydrates [fodmaps] exacerbate functional gastrointestinal symptoms in patients with inflammatory bowel disease: A randomised, double-blind, placebo-controlled, cross-over, re-challenge trial. J Crohn's Colitis. 2017 Dec;11(12):1420-9.

131 Herfarth HH, Martin CF, Sandler RS, Kappelman MD, Long MD. Prevalence of a gluten-free diet and improvement of clinical symptoms in patients with inflammatory bowel diseases. Inflamm Bowel Dis. $2014 \mathrm{Jul}$; 20(7):1194-7.

132 Kim HS, Patel KG, Orosz E, Kothari N, Demyen MF, Pyrsopoulos N, et al. Time trends in the prevalence of celiac disease and gluten-free diet in the us population: results from the national health and nutrition examination surveys 2009-2014. JAMA Intern Med. 2016 Nov;176(11):1716-7.

133 Skodje GI, Sarna VK, Minelle IH, Rolfsen KL, Muir JG, Gibson PR, et al. Fructan, rather than gluten, induces symptoms in patients with self-reported non-celiac gluten sensitivity. Gastroenterology. 2018;154:529-39. e2.

134 Chassaing B, Koren O, Goodrich JK, Poole AC, Srinivasan S, Ley RE, et al. Dietary emulsifiers impact the mouse gut microbiota promoting colitis and metabolic syndrome. Nature. 2015 Mar;519(7541): 92-6.

135 Ruiz PA, Morón B, Becker HM, Lang S, Atrott K, Spalinger MR, et al. Titanium dioxide nanoparticles exacerbate DSS-induced colitis: role of the NLRP3 inflammasome. Gut. 2017 Jul;66(7):1216-24.

136 Rodriguez-Palacios A, Harding A, Menghini P, Himmelman C, Retuerto M, Nickerson $\mathrm{KP}$, et al. The artificial sweetener splenda promotes gut proteobacteria, dysbiosis, and myeloperoxidase reactivity in crohn's disease-like ileitis. Inflamm Bowel Dis. 2018 Apr;24(5):1005-20. 
137 Torres J, Ellul P, Langhorst J, Mikocka-Walus A, Barreiro-de Acosta M, Basnayake C, et al. European crohn's and colitis organisation topical review on complementary medicine and psychotherapy in inflammatory bowel disease. J Crohns Colitis. 2019 May 27;13(6): 673-85e.

138 Gubatan J, Mitsuhashi S, Zenlea T, Rosenberg L, Robson S, Moss AC. Low serum vitamin $\mathrm{d}$ during remission increases risk of clinical relapse in patients with ulcerative colitis. Clin Gastroenterol Hepatol. 2017 Feb;15(2):240-46.e1.

139 Jørgensen SP, Hvas CL, Agnholt J, Christensen LA, Heickendorff L, Dahlerup JF. Active Crohn's disease is associated with low vitamin D levels. J Crohn's Colitis. 2013 Nov;7(10):e407-13.

140 Meckel K, Li YC, Lim J, Kocherginsky M, Weber C, Almoghrabi A, et al. Serum 25-hydroxyvitamin D concentration is inversely associated with mucosal inflammation in patients with ulcerative colitis. Am J Clin Nutr. 2016 Jul;104(1):113-20.

141 Kabbani TA, Koutroubakis IE, Schoen RE, Ramos-Rivers C, Shah N, Swoger J, et al. Association of vitamin d level with clinical status in inflammatory bowel disease: A 5-year longitudinal study. Am J Gastroenterol. 2016 May;111(5):712-9.

142 Jørgensen SP, Agnholt J, Glerup H, Lyhne S, Villadsen GE, Hvas CL, et al. Clinical trial: vitamin D3 treatment in Crohn's disease - a randomized double-blind placebo-controlled study. Aliment Pharmacol Ther. 2010 Aug;32(3):377-83.

143 Yang L, Weaver V, Smith JP, Bingaman S, Hartman TJ, Cantorna MT. Therapeutic effect of vitamin d supplementation in a pilot study of Crohn's patients. Clin Transl Gastroenterol. 2013 Apr;4(4):e33.

144 Garg M, Hendy P, Ding JN, Shaw S, Hold G, Hart A. The effect of vitamin d on intestinal inflammation and faecal microbiota in patients with ulcerative colitis. J Crohn's Colitis. 2018 Jul;12(8):963-72.

145 Ananthakrishnan AN. Vitamin d and inflammatory bowel disease. Gastroenterol Hepatol (N Y). 2016 Aug;12(8):513-5.

146 Montrose DC, Horelik NA, Madigan JP, Stoner GD, Wang LS, Bruno RS, et al. Antiinflammatory effects of freeze-dried black raspberry powder in ulcerative colitis. Carcinogenesis. 2011 Mar;32(3):343-50.

147 Kang Y, Yang G, Zhang S, Ross CF, Zhu MJ. Goji berry modulates gut microbiota and alleviates colitis in il-10-deficient mice. Mol Nutr Food Res. 2018 Nov;62(22): e1800535.

148 Aghdassi E, Wendland BE, Steinhart AH, Wolman SL, Jeejeebhoy K, Allard JP. Antioxidant vitamin supplementation in Crohn's disease decreases oxidative stress. a randomized controlled trial. Am J Gastroenterol. 2003 Feb;98(2):348-53.

149 Langmead L, Makins RJ, Rampton DS. Antiinflammatory effects of aloe vera gel in hu- man colorectal mucosa in vitro. Aliment Pharmacol Ther. 2004 Mar;19(5):521-7.

150 Langmead L, Feakins RM, Goldthorpe S, Holt H, Tsironi E, De Silva A, et al. Randomized, double-blind, placebo-controlled trial of oral aloe vera gel for active ulcerative colitis. Aliment Pharmacol Ther. 2004 Apr; 19(7):739-47.

151 Ju S, Ge Y, Li P, Tian X, Wang H, Zheng X, et al. Dietary quercetin ameliorates experimental colitis in mouse by remodeling the function of colonic macrophages via a heme oxygenase-1-dependent pathway. Cell Cycle. 2018;17(1):53-63.

152 Langhorst J, Varnhagen I, Schneider SB, Albrecht U, Rueffer A, Stange R, et al. Randomised clinical trial: a herbal preparation of myrrh, chamomile and coffee charcoal compared with mesalazine in maintaining remission in ulcerative colitis-a doubleblind, double-dummy study. Aliment Pharmacol Ther. 2013 Sep;38(5):490-500.

153 Authors; Collaborators. Updated S3-Guideline Ulcerative Colitis. German Society for Digestive and Metabolic Diseases (DGVS). Z Gastroenterol. 2019 Feb;57(2):162-241.

154 Alizadeh F, Javadi M, Karami AA, Gholaminejad F, Kavianpour M, Haghighian HK. Curcumin nanomicelle improves semen parameters, oxidative stress, inflammatory biomarkers, and reproductive hormones in infertile men: A randomized clinical trial. Phytother Res. 2018 Mar;32(3): 514-21.

$155 \mathrm{Xu}$ YX, Pindolia KR, Janakiraman N, Noth CJ, Chapman RA, Gautam SC. Curcumin, a compound with anti-inflammatory and anti-oxidant properties, down-regulates chemokine expression in bone marrow stromal cells. Exp Hematol. 1997 May;25(5):413-22.

156 Lang A, Salomon N, Wu JC, Kopylov U, Lahat A, Har-Noy O, et al. Curcumin in combination with mesalamine induces remission in patients with mild-to-moderate ulcerative colitis in a randomized controlled trial. Clin Gastroenterol Hepatol. 2015;13: 1444-9.e1.

157 Moss AC. Curcumin for maintenance therapy in ulcerative colitis. Clin Gastroenterol Hepatol. Association 2007;5:642; author reply 642.

158 Hanai H, Iida T, Takeuchi K, Watanabe F, Maruyama Y, Andoh A, et al. Curcumin maintenance therapy for ulcerative colitis: randomized, multicenter, double-blind, placebo-controlled trial. Clin Gastroenterol Hepatol. 2006 Dec;4(12):1502-6.

159 Kumar S, Ahuja V, Sankar MJ, Kumar A, Moss AC. Curcumin for maintenance of remission in ulcerative colitis. Cochrane Database Syst Rev. 2012 Oct;10:CD008424.

$160 \mathrm{http} / / /$ apps.who.int/food-additives-contaminants-jecfa-database/chemical. aspx? chemID $=638$.

161 Shoba G, Joy D, Joseph T, Majeed M, Rajendran R, Srinivas PS. Influence of piperine on the pharmacokinetics of curcumin in ani- mals and human volunteers. Planta Med. 1998 May;64(4):353-6.

162 Sarfraz RM, Khan H, Maheen S, Afzal S, Akram MR, Mahmood A, et al. Plantago ovata: A comprehensive review on cultivation, biochemical, pharmaceutical and pharmacological aspects. Acta Pol Pharm. 2017 May;74(3):739-46.

163 Fernández-Bañares F, Hinojosa J, SánchezLombraña JL, Navarro E, Martínez-Salmerón JF, García-Pugés A, et al.; Spanish Group for the Study of Crohn's Disease and Ulcerative Colitis (GETECCU). Randomized clinical trial of Plantago ovata seeds (dietary fiber) as compared with mesalamine in maintaining remission in ulcerative colitis. Am J Gastroenterol. 1999 Feb;94(2):427-33.

164 Nguyen GC, Munsell M, Harris ML. Nationwide prevalence and prognostic significance of clinically diagnosable protein-calorie malnutrition in hospitalized inflammatory bowel disease patients. Inflamm Bowel Dis. 2008 Aug; 14(8):1105-11.

165 Gallinger ZR, Rumman A, Pivovarov K, Fortinsky KJ, Steinhart AH, Weizman AV. Frequency and variables associated with fasting orders in inpatients with ulcerative colitis: the audit of diet orders-ulcerative colitis (adore-uc) study. Inflamm Bowel Dis. 2017 Oct;23(10):1790-5.

166 Vavricka SR, Rogler G. Intestinal absorption and vitamin levels: is a new focus needed? Dig Dis. 2012;30(Suppl 3):73-80.

167 Niepel D, Klag T, Malek NP, Wehkamp J. Practical guidance for the management of iron deficiency in patients with inflammatory bowel disease. Therap Adv Gastroenterol. 2018 Apr; 11:1756284818769074.

168 Madanchi M, Fagagnini S, Fournier N, Biedermann L, Zeitz J, Battegay E, et al.; Swiss IBD Cohort Study Group. The relevance of vitamin and iron deficiency in patients with inflammatory bowel diseases in patients of the swiss ibd cohort. Inflamm Bowel Dis. 2018 Jul;24(8):1768-79.

169 Knovich MA, Storey JA, Coffman LG, Torti SV, Torti FM. Ferritin for the clinician. Blood Rev. 2009 May;23(3):95-104.

170 Short MW, Domagalski JE. Iron deficiency anemia: evaluation and management. Am Fam Physician. 2013 Jan;87(2):98-104.

171 Anker SD, Comin Colet J, Filippatos G, Willenheimer R, Dickstein K, Drexler H, et al.; FAIR-HF Trial Investigators. Ferric carboxymaltose in patients with heart failure and iron deficiency. N Engl J Med. 2009 Dec; 361(25):2436-48.

172 Eisenga MF, Bakker SJ, Gaillard CA. Definition of functional iron deficiency and intravenous iron supplementation. Lancet Haematol. 2016 Nov;3(11):e504.

173 Evstatiev R, Marteau P, Iqbal T, Khalif IL, Stein J, Bokemeyer B, et al. FERGIcor, a randomized controlled trial on ferric carboxymaltose for iron deficiency anemia in inflammatory bowel disease. Gastroenterology. 2011;141:846-53.e1-2. 
174 Hurrell R, Egli I. Iron bioavailability and dietary reference values. Am J Clin Nutr. 2010 May;91(5):1461S-7S.

175 Camaschella C. Iron deficiency. Blood. 2019 Jan;133(1):30-9.

176 Zimmermann MB, Chassard C, Rohner F, N'goran EK, Nindjin C, Dostal A, et al. The effects of iron fortification on the gut microbiota in African children: a randomized controlled trial in Cote d'Ivoire. Am J Clin Nutr. 2010 Dec;92(6):1406-15.

177 Jaeggi T, Kortman GA, Moretti D, Chassard C, Holding P, Dostal A, et al. Iron fortification adversely affects the gut microbiome, increases pathogen abundance and induces intestinal inflammation in Kenyan infants. Gut. 2015 May;64(5):731-42.

178 Mahalhal A, Williams JM, Johnson S, Ellaby N, Duckworth CA, Burkitt MD, et al. Oral iron exacerbates colitis and influences the intestinal microbiome. PLoS One. 2018 Oct; 13(10):e0202460.

179 Erichsen K, Ulvik RJ, Nysaeter G, Johansen J, Ostborg J, Berstad A, et al. Oral ferrous fumarate or intravenous iron sucrose for patients with inflammatory bowel disease. Scand J Gastroenterol. 2005 Sep;40(9):105865.

180 de Silva AD, Tsironi E, Feakins RM, Rampton DS. Efficacy and tolerability of oral iron therapy in inflammatory bowel disease: a prospective, comparative trial. Aliment Pharmacol Ther. 2005 Dec;22(11-12):1097105.

181 Gasche C, Ahmad T, Tulassay Z, Baumgart DC, Bokemeyer B, Büning C, et al.; AEGIS Study Group. Ferric maltol is effective in correcting iron deficiency anemia in patients with inflammatory bowel disease: results from a phase-3 clinical trial program. Inflamm Bowel Dis. 2015 Mar;21(3):57988.

182 Schmidt C, Ahmad T, Tulassay Z, Baumgart DC, Bokemeyer B, Howaldt S, et al.; AEGIS Study Group. Ferric maltol therapy for iron deficiency anaemia in patients with inflammatory bowel disease: long-term extension data from a Phase 3 study. Aliment Pharmacol Ther. 2016 Aug;44(3):259-70.

183 Stoffel NU, Cercamondi CI, Brittenham G, Zeder C, Geurts-Moespot AJ, Swinkels DW, et al. Iron absorption from oral iron supplements given on consecutive versus alternate days and as single morning doses versus twice-daily split dosing in iron-depleted women: two open-label, randomised controlled trials. Lancet Haematol. 2017 Nov; 4(11):e524-33.

184 Girelli D, Nemeth E, Swinkels DW. Hepcidin in the diagnosis of iron disorders. Blood. 2016 Jun;127(23):2809-13.

185 Dignass AU, Gasche C, Bettenworth D, Birgegård G, Danese S, Gisbert JP, et al.; European Crohn's and Colitis Organisation
[ECCO]. European consensus on the diagnosis and management of iron deficiency and anaemia in inflammatory bowel diseases. J Crohn's Colitis. 2015 Mar;9(3):211-22.

186 Litton E, Xiao J, Ho KM. Safety and efficacy of intravenous iron therapy in reducing requirement for allogeneic blood transfusion: systematic review and meta-analysis of randomised clinical trials. BMJ. 2013 Aug;347: f4822.

187 Maynor L, Brophy DF. Risk of infection with intravenous iron therapy. Ann Pharmacother. 2007 Sep;41(9):1476-80.

188 Kruis W, Phuong Nguyen G. Iron deficiency, zinc, magnesium, vitamin deficiencies in crohn's disease: substitute or not? Dig Dis. 2016;34(1-2):105-11.

189 Battat R, Kopylov U, Szilagyi A, Saxena A, Rosenblatt DS, Warner M, et al. Vitamin B12 deficiency in inflammatory bowel disease: prevalence, risk factors, evaluation, and management. Inflamm Bowel Dis. 2014 Jun; 20(6):1120-8.

190 Devalia V, Hamilton MS, Molloy AM; British Committee for Standards in Haematology. Guidelines for the diagnosis and treatment of cobalamin and folate disorders. Br J Haematol. 2014 Aug;166(4):496-513.

191 Shipton MJ, Thachil J. Vitamin B12 deficiency - A 21st century perspective. Clin Med (Lond). 2015 Apr; 15(2):145-50.

192 M'Koma AE. Follow-up results of hematology data before and after restorative proctocolectomy. Clinical outcome. Dis Colon Rectum. 1994 Sep;37(9):932-7.

193 Chetcuti Zammit S, Ellul P, Girardin G, Valpiani D, Nielsen KR, Olsen J, et al. Vitamin $\mathrm{D}$ deficiency in a European inflammatory bowel disease inception cohort: an Epi-IBD study. Eur J Gastroenterol Hepatol. 2018 Nov;30(11):1297-303.

194 Frigstad SO, Høivik M, Jahnsen J, Dahl SR, Cvancarova M, Grimstad T, et al. Vitamin D deficiency in inflammatory bowel disease: prevalence and predictors in a Norwegian outpatient population. Scand J Gastroenterol. 2017 Jan;52(1):100-6.

195 Lee S, Metcalfe A, Raman M, Leung Y, Aghajafari F, Letourneau N, et al. Pregnant women with inflammatory bowel disease are at increased risk of vitamin d insufficiency: A cross-sectional study. J Crohn's Colitis. 2018 May;12(6):702-9.

196 Del Pinto R, Pietropaoli D, Chandar AK, Ferri C, Cominelli F. Association between inflammatory bowel disease and vitamin $\mathrm{d}$ deficiency: A systematic review and metaanalysis. Inflamm Bowel Dis. 2015 Nov; 21(11):2708-17.

197 Margulies SL, Kurian D, Elliott MS, Han Z. Vitamin D deficiency in patients with intestinal malabsorption syndromes-think in and outside the gut. J Dig Dis. 2015 Nov; 16(11):617-33.
198 Murphy EW, Willis BW, Watt BK. Provisional tables on the zinc content of foods. J Am Diet Assoc. 1975 Apr;66(4):345-55.

199 Foster M, Chu A, Petocz P, Samman S. Effect of vegetarian diets on zinc status: a systematic review and meta-analysis of studies in humans. J Sci Food Agric. 2013 Aug;93(10): 2362-71.

200 Lim KH, Riddell LJ, Nowson CA, Booth AO, Szymlek-Gay EA. Iron and zinc nutrition in the economically-developed world: a review. Nutrients. 2013 Aug;5(8):3184-211.

201 Wolman SL, Anderson GH, Marliss EB, Jeejeebhoy KN. Zinc in total parenteral nutrition: requirements and metabolic effects. Gastroenterology. 1979 Mar;76(3):458-67.

202 Han YM, Yoon H, Lim S, Sung MK, Shin $\mathrm{CM}$, Park YS, et al. Risk factors for vitamin $\mathrm{d}$, zinc, and selenium deficiencies in korean patients with inflammatory bowel disease. Gut Liver. 2017 May;11(3):363-9.

203 Filippi J, Al-Jaouni R, Wiroth JB, Hébuterne $\mathrm{X}$, Schneider SM. Nutritional deficiencies in patients with Crohn's disease in remission. Inflamm Bowel Dis. 2006 Mar;12(3):18591.

204 Fritz J, Walia C, Elkadri A, Pipkorn R, Dunn RK, Sieracki R, et al. A systematic review of micronutrient deficiencies in pediatric inflammatory bowel disease. Inflamm Bowel Dis. 2019 Feb;25(3):445-59.

205 Siva S, Rubin DT, Gulotta G, Wroblewski K, Pekow J. Zinc deficiency is associated with poor clinical outcomes in patients with inflammatory bowel disease. Inflamm Bowel Dis. 2017 Jan;23(1):152-7.

206 Greuter T, Franc Y, Kaelin M, Schoepfer AM, Schreiner P, Zeitz J, et al. Low serum zinc levels predict presence of depression symptoms, but not overall disease outcome, regardless of atg16l1 genotype in crohn's disease patients. Therap Adv Gastroenterol. 2018 Feb 19;11:1756283X18757715.

207 de Benoist B, Darnton-Hill I, Davidsson L, Fontaine O, Hotz C. Conclusions of the joint who/unicef/iaea/izincg interagency meeting on zinc status indicators. Food Nutr Bull. 2007 Sep;28(3 Suppl):S480-4.

208 Jeejeebhoy K. Zinc: an essential trace element for parenteral nutrition. Gastroenterology. 2009 Nov;137(5 Suppl):S7-12.

209 Wieringa FT, Dijkhuizen MA, Fiorentino M, Laillou A, Berger J. Determination of zinc status in humans: which indicator should we use? Nutrients. 2015 May;7(5):3252-63.

210 Rossi RE, Whyand T, Murray CD, Hamilton MI, Conte D, Caplin ME. The role of dietary supplements in inflammatory bowel disease: a systematic review. Eur J Gastroenterol Hepatol. 2016 Dec;28(12):1357-64.

211 Duncan A, Yacoubian C, Watson N, Morrison I. The risk of copper deficiency in patients prescribed zinc supplements. J Clin Pathol. 2015 Sep;68(9):723-5. 